\title{
Delineation of Effectors Impact on The Human Brain Derived Phosphoribosylpyrophosphate Synthetase-1 Activity
}

\author{
Kristine Edgar Danielyan* and Samvel Grigoriy Chailyan \\ H Bunitain Institute of Biochemistry, Armenia \\ *Corresponding author: Kristine Edgar Danielyan, H Bunitain Institute of Biochemistry, National Academy of Science of Armenia, \\ Armenia
}

\begin{abstract}
ARTICLE INFO
Received: 靟 December 09, 2019

Published: 慧 December 18, 2019

Citation: Kristine Edgar Danielyan, Samvel

\section{ABSTRACT}

Objective: Phosphoribosylpyrophosphate synthetase-1 (PRPS-1; EC=2.7.6.1) catalyzes the phosphoribosylation of ribose 5-phosphate to 5-phosphoribosyl-1pyrophosphate, which is the key regulative enzyme of the purine and pyrimidine synthesis. We aimed mainly to define the impact of the microelements (mostly essential metals ions) on the PRPS- 1 in the setting of glioblastoma (GB).
\end{abstract} Grigoriy Chailyan. Delineation of Effectors Impact on The Human Brain Derived Phosphoribosylpyrophosphate Synthetase-1 Activity. Biomed J Sci \& Tech Res 24(1)2019. BJSTR. MS.ID.003988.

Keywords: Phosphoribosylpyrophosphate Synthetase-1; Microelements; Metal Ions; Adenoisne Deaminase; Xanthine Oxidoreductase; Glioblastoma

Abbreviations: BSA: Bovine Serum Albumin, GB: Glioblastoma, OPT: Orotate Phosphoribolsyl-Transferase, XDH: Xanthine Dehydrogenase
Methods: For purification of the PRPS-1 we used the tissue processing, gelfiltration, dialysis, affinity chromatography, RP-HPLC methods. Primer cell culture of the GB cells was maintained by the well-established methods of M. Mattson, 1990. Cells were injected into the cortex of the rat brains.

Results: Adenosine, high concentration of $\mathrm{SO}^{2-}$ was acting as the inhibitors for the PRPS- $1(98,7634 \pm 1,2450,93,2074 \pm 0,0932 ; \mathrm{p}<0.05)$. The other agents $\left(\mathrm{Co}^{2+}, \mathrm{Cu}^{2+}\right.$, $\mathrm{Mg}^{2+}$ ) were possessing with the activating abilities on the same enzyme. In the settings of the GB high concentrations of SO42- were diminishing the activity of PRPS-1 in the experimental GB settings in comparison with the control. It was notable elevation of the adenosine deaminase as well as xanthine oxidoreductase activities in the same groups in comparison with the control animals.

Conclusion: The inhibitors of PRPS-1 might be useful in the setting of the cancer prevention, particularly for GB.

\section{Introduction}

Phosphoribosylpyrophosphate synthetase-1 [PRPS-1; $\mathrm{EC}=2.7 .6 .1$ ) catalyzes the phosphoribosylation of ribose5-phosphate to 5-phosphoribosyl-1-pyrophosphate, which is necessary for the salvage pathways of purine and pyrimidine, pyridine nucleotide cofactors NAD and NADP, the amino acids histidine and tryptophan biosynthesis [1,2]. It is regulative enzyme, responsible for the synthesis of purine and pyrimidine. Regulation of this particular enzyme might be dependent on the effectors, including metal ions. Generally, metal ions are vital for functionality (metallo-enzyme activity, protein stabilization etc.) and maintenance of nervous tissue. The overload of copper lead to neurodegeneration in Menkes and Wilson's disease, increased brain aging, dwindle cognitive and epileptic seizures due to altered brain zinc homeostasis. Presence of dyshomeostasis of essential and nonessential metals is considered vital in sporadic neurodegeneration. Increased levels of iron and copper in tissue are directly related to increased inflammatory markers and oxidative stress in affected brains. The rich metal (zinc, iron, copper) concentration in degenerated protein aggregates and plaques demonstrates the link between metals and neurodegenerative pathologies. Changes in aggregation properties (a-synuclein and amyloid-b) lead to complex protein formation owing to the presence of aluminium, copper and iron [3].

Super activity of PRPS is an inherited X-chromosome-linked disorder [4] and the excessive enzymatic activity is associated 
with uric acid overproduction, gout and neurodevelopmental abnormalities [5-8]. Thus, in case of the genetic pathologies the regulation of PRPS-1 is essential. Three classes of PRSPs have been reported which are divided based on their dependence on phosphate ions for activity, their allosteric regulation mechanism and their diphosphoryl donor specificity [9-12]. Most PRSPs belong to the class I, which require $\mathrm{Mg} 2+$ and phosphate for enzymatic activity, but can be inhibited allosterically by ADP and possibly other nucleotides [13-20]. Class II PRSs are found specifically in plants which are not dependent on phosphate for activity and lack an allosteric site for ADP [9-10]. Recently, a novel class III PRS has been identified from Methanocaldococcus jannaschii which is activated by phosphate and uses ATP and dATP as a diphosphoryl donor, but also lacks an allosteric site for ADP [12]. HPRPSs (human PRP synthetases) have three isoforms that share very high sequence identity (95.0\% between hPRPS1 and hPRPS2; $94.3 \%$ between hPRPS1 and hPRPS3; and 91.2\% between hPRPS2 and hPRPS3 respectively) [21-24].

Enzyme requires phosphate for activation and uses $\mathrm{Mg}_{2}+$ [14,25-27]. The crystallization of hPRPS1 has recently been reported [27]. Interestingly, in addition to binding at the R5P binding site and the allosteric site defined previously in bsPRS, an extra SO $4^{2-}$ ion is found to bind at a new allosteric site at the dimer interface. Structural and biochemical data together reveal new insights into the allosteric regulatory mechanism of hPRPS1 and possibly other eukaryotic PRPSs (except for class II plant PRSs) [28]. In our previ- ous publications we have proposed that activation of PRPS- 1 in the brain might trigger the increase in the rate of the purine and pyrimidine biosynthesis and stimulate the regenerative processes after experimental stroke in rats [29]. The treatment of the animals with the phosphates after experimental stroke reflecting conditions, we have noticed the elevation of the Ki-67 positive neurons in the brain as well as the decrease in the BBB (blood brain barrier) damage process and Evans Blue extravasation [29].

In our current study we were aiming to define non-organic and organic compounds, which are influencing on the activity of the PRPS-1. In addition, we developed the methods for Orotate Phosphoribolsyl-Transferase (OPT) and PRPS-1 purification and creation of the kit (Figure 1), measuring the PRPS-1 activity in blood as well as in tissues. We established the Glioblastoma (GB) model and evaluated the inhibitor of PRPS-1 - high and low concentration of SO4- ions. Along with the PRPS- 1 we measured the adenosine deaminase -2 (ADA-2) as well as Xanthine Oxidoreductase (XOR) activities as the potential markers of GB.

\section{Material and Methods}

The all reagents were purchased from Sigma/Aldrich or/and Santa Cruz Biotechnology, Inc. We have created the kit for the determination of the PRPS- 1 activity. The entire idea of the leaded reactions for the final measurement of the enzyme activity is presented on the (Figure 1).

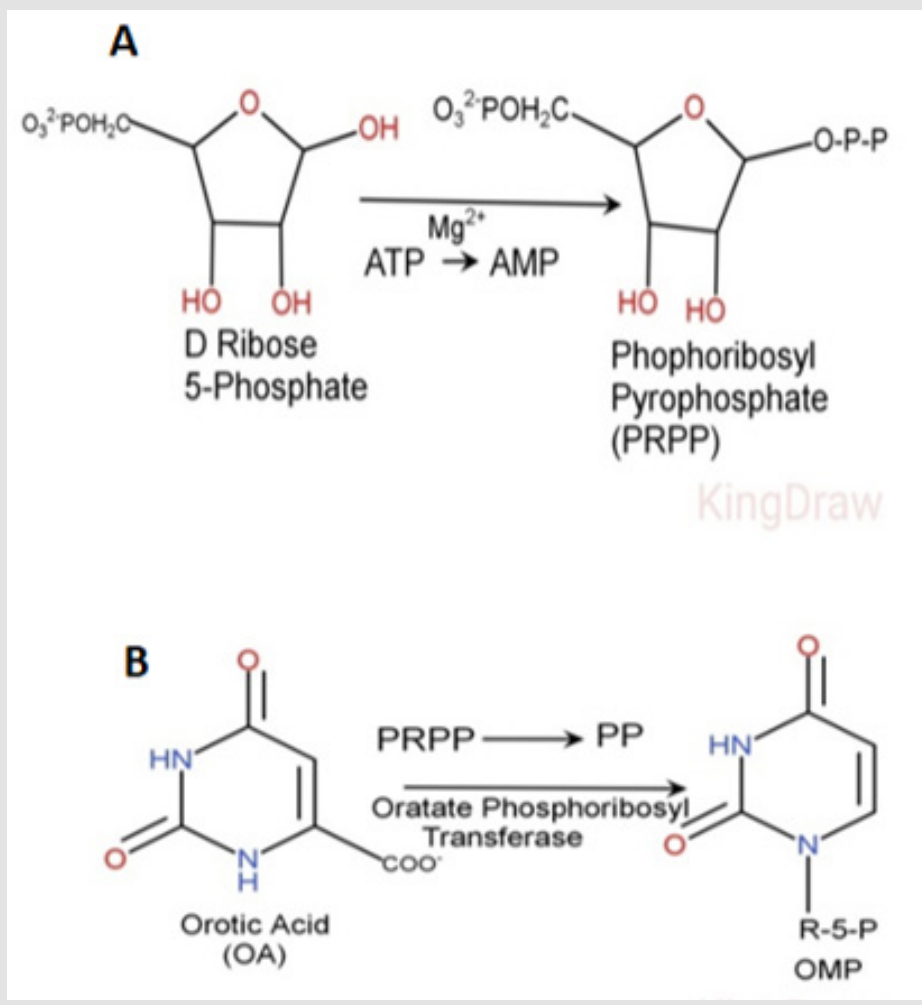

Figure 1: The synthesis of PRPS from D-Ribose 5-Phosphate by the PRPS-1 and the following formation of the Ribose 5-Phospahateand PP in the presence of OPT. 


\section{Purification of Orotate Phosphoribolsyl-Transferase (OPT)}

The brain tissue, predominantly cortical part of the human brain was obtained from the carcasses of the death bodies. The tissue was desiccated in accordance to the permission of the relatives to use the tissues for the bench-top scientific experiments. The experimental procedures with the human tissues was approved by the Ethical Committee of the $\mathrm{H}$ Buniatian Institute of Biochemistry of the National Academy of Science of Armenia (Reference Letter N 2; Active International Registrations' Numbers: IRB0001621, IORG 0009782). Around 200-250g of the tissue was washed with the basic buffer, containing $10 \mathrm{mM}$ Tris buffer, I mM EDTA, $1 \mathrm{mM}$ trypsine inhibitor obtained from the soy beans and $0.001 \mathrm{M} \mathrm{KNaC}_{4} \mathrm{H}_{4} \mathrm{O}_{6} \times 4 \mathrm{H}_{2} \mathrm{O}$ ( $\left.\mathrm{pH}=7.8\right)$. After all, we have performed glass-glass homogenization in the cold conditions $\left(4^{\circ} \mathrm{C}\right)$ with the basic buffer, containing sucrose. The homogenate was centrifuged at $14,000 \mathrm{~g}$ for 30 minutes at $4^{\circ} \mathrm{C}$ and the resultant supernatant fraction was used as the starting material.

The proteins were precipitated with $50 \%$ ammonium sulfate. After centrifugation at $\mathrm{g}=14000$ the protein fraction was placed into the dialysis bags against $0.1 \mathrm{M}$ PBS. The pooled fractions were than fractionated with the cold acetone $\left(-20^{\circ} \mathrm{C}\right)$. Cold acetone was added with vigorous stirring to the enzyme fraction until an acetone/ homogenate would reach to the $43: 57$ ratio. The preparation was immediately centrifuged at $5000 \mathrm{~g}$ for 10 minutes at $4^{\circ} \mathrm{C}$. The resultant supernatant was discarded and the pellet resuspended in $50 \mathrm{ml}$ basic buffer. The ready fraction was applied to $300 \mathrm{ml}$ of DEAE-Sephacel preequilibrated with basic buffer. After application, the gel was washed with three $200 \mathrm{ml}$ aliquots of basic buffer and the enzyme was then eluted by washing the column with $100 \mathrm{ml}$ aliquots of $0.05-0.2 \mathrm{M} \mathrm{NaCl}$ basic buffer. The fractions were collected and assayed for the enzyme activity. The protein fractions were placed to dialysis against 0.1MPBS. The fractions were applied to a $35 \mathrm{x}$ 2.5sm DEAE-Sephacel column preequilibrated with buffer.

Elution was performed with $0.05-0.2 \mathrm{M} \mathrm{NaCl}$ gradient in basic buffer. The fraction were collected and assayed for the enzyme activity. Further, the fractions were concentrated with 50\% ammonium sulfate and placed for dialysis against 0.1M PBS. Affinity chromatography was performed by the utility of the modified Cibacron Blue gel (Santa Cruz Biotechnology, USA). Cibacron Blue contains amino-groups on the surface. Aldehyde might bind amino groups of orotic acid and the amino-groups of Cibacron Blue with each other. It was used $0.001 \%$ orotic acid (Santa Cruz Biotechnoloy, USA) for the binding purpose. Due to partial structural modifications orotic acid doesn't bind permanently with OPT and in conditions of application of the high orotic acid solution (elution with the $0.01 \%$ ) the bound OPT might be washed out. The effectively of the binding was determined by the scanning of the orotic acid and washed out eluent after addition of the same quantity of orotic acid on the gel vs pure orotic acid solution with the same amount of the acid. Final washed out eluent was containing negligible amount of orotic acid, which proved the fact of the binding of the applied orotic acid with the Cibacron Blue by the glutaraldehyde (50\%, Sigma-Aldrich). Purity of the obtained enzymes was detected by the RP-HPLC.

\section{Purification of the PRPS-1}

The enzyme was purified from the human brain cortex. The routine purification procedures were the same as for the OPT. Semi-affinity chromatography was performed by the utility of the Cibacron Blue gel (Santa Cruz Biotechnology, USA). The elution was performed by the $44 \%$ NAD+ (Sigma-Aldrich). Purities of the obtained enzymes were detected by the RP-HPLC.

\section{Measurement of PRPS-1 activity}

Purified PRPS-1 activity was determined in the presence of purified OPT, orotate $(0.2 \mathrm{mM})$, ATP $(0.3 \mathrm{mM})$, Ribose-5-phosphate ( $4 \mathrm{mM})$, magnesium ions, $1 \mathrm{M}$ Tris buffer ( $\mathrm{pH}=7.7), 36.6 \mathrm{C} \bullet$ after 60 minutes incubation and detection at the $\lambda=730 \mathrm{~nm}$ by the utility of the Cary 60 spectrophotometer (Agilent, USA). Coloring solution was containing the concentrated sulfuric acid, $4 \%$ ascorbic acid, $0.3 \%$ anthimony potassium tartrate and sodium molybdate (4.5\%). The absorption was detected by the Cary 60 Spectrophotometer (Agilent, USA) at $730 \mathrm{~nm}$ wavelength. For the calculation of the specific activity of the enzymes it was applied the Bradford method, determining the quantity of the proteins in solution.

RP-HPLC: For the final detection of the purity of the obtained enzymes it was used Shimadzu LC -20 chromatograph, supplied with UV-Vis detector SM 5000 and the C18 RP-colums of the Avex, Waters, Symmetry companies. The speed of the elution was $2 \mathrm{ml} / \mathrm{min}$. As the eluents there was used degased water as well as acetonitrile (Sigma-Aldrich) in the ratio of 20:80. The enzymes absorption was detected at $280 \mathrm{~nm}$. The analyses were performed in 10 minutes (Suppl. Figure 1). 

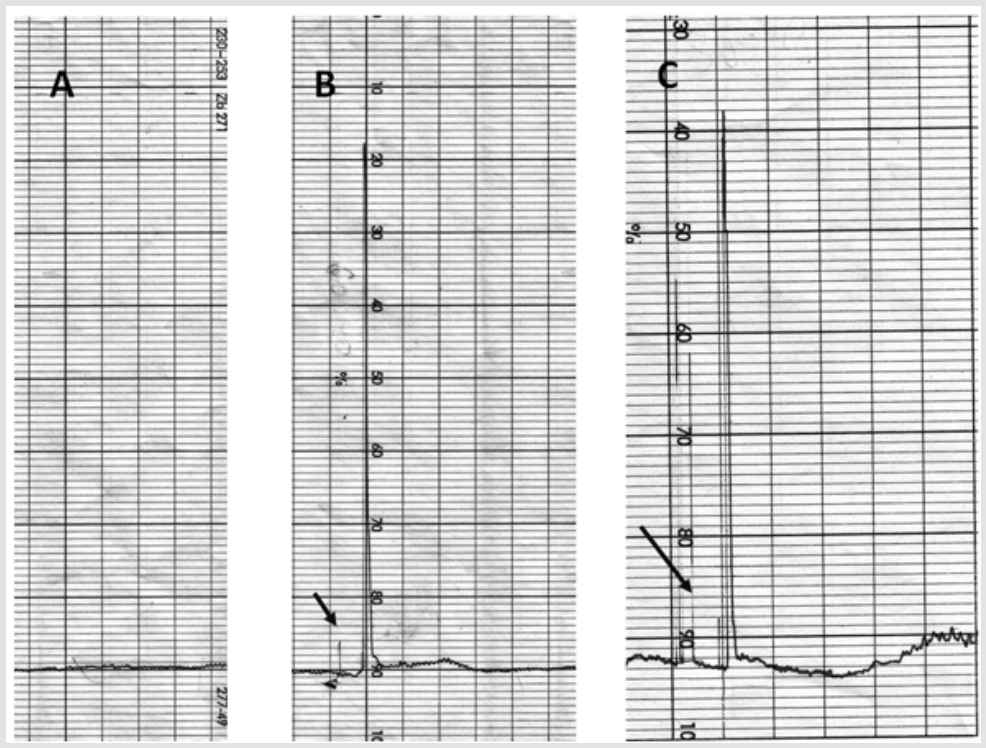

Supplementary Figure 1: RP-HPLC evaluation of purified PRPS-1 and OPT.
A. Background of the eluent.
B. PRPS-1.
C. OPT. The arrows are pointing the draft for the starting point of the analyses.

\section{Methyl Green}

Methyl green $(2 \%(\mathrm{w} / \mathrm{v})$ in $0.1 \mathrm{M} \mathrm{NaOAc}, \mathrm{pH} 4.2$ was prepared. It was mixed $918 \mathrm{ml}$ of $0.1 \mathrm{~N}$ acetic acid with $331 \mathrm{~mL}$ of $0.1 \mathrm{M} \mathrm{NaOAc}$ and adjust $\mathrm{pH}$ to 4.2 with $\mathrm{NaOH}$. The final solution was containing $25 \mathrm{gm}$ of methyl green dye. The solution was filtered through Whatman \#2 filter paper. After application of the solution on the frozen slices for 5-10 minutes, they were washed and visualized by the light microscopy (Trinocular; Boeco, Germany, 1800 magnification) [30].

\section{Cell Culturing}

GB tissue was withdrawn and placed in Neurobasal medium (NB, prenatal, Gibco Life Technologies) containing 0.05\% Bovine Serum Albumin (BSA). The tissue was isolated and incubated at $37^{\circ} \mathrm{C}$ for $20 \mathrm{~min}$ in NB containing $0.05 \%$ BSA, $0.15 \%$ trypsine. Tissue was resuspended in fresh NB and mechanically disintegrated using a Pasteur pipette. The supernatant was discarded and the cell suspension was resuspended in NB medium containing 1\% BSA. This procedure was repeated 3 times. Human brain cells were collected (1,000rpm, $10 \mathrm{~min})$, washed and cultured at $37^{\circ} \mathrm{C}, 5 \% \mathrm{CO}_{2}$ in $35 \mathrm{~mm}$ Petri dishes pre-coated with poly-L-lysin (Sigma) containing $0.09 \% \mathrm{Na} 2 \mathrm{HPO} 4,1 \%$ glucose, $0.4 \% \mathrm{KCl}, 0.06 \% \mathrm{KH}_{2} \mathrm{PO}_{4}, 0.4 \%$ $\mathrm{MgSO}_{4}$ x $7 \mathrm{H} 2 \mathrm{O}$ and $0.001 \%$ gentamicin sulfate. A day later the medium was replaced by NB containing 2\% B27-supplement (Gibco) and the cells' number was calculated on 1st and 3rd days [31].

\section{Animal Model of GB}

For the entire in vivo study it was used 70 animals. The all experimental procedures were approved by Ethical Committee of the Institute of Biochemistry, National Academy of Science of
Armenia. The animals were anesthetized by administration of pentobarbital $10 \mathrm{mg} / 100 \mathrm{mg}$ of weigh $\mathrm{kg}$, injected I.P. using a hypodermic needle. During surgery cranial and rectal temperature continuously were controlled as these parameters reflecting the normal animal physiological state. The body as well as cranial temperatures was sustained for 36.6 C The hair layer of the white laboratory rats head was removed and the skin before the incision was cleaned with ethanol. The rats were placed in a stereotaxic frame (Poland), and a specially fabricated 27-gauge stainless steel cannula with $30^{\circ}$ bevel was introduced after limited craniotomy through a burr hole into the midcerebral cortex.

Cells were in the amount of 8000 injected after limited craniotomy into the brain parenchyma by the following coordinates from bregma: $2 \mathrm{~mm}$ lateral to midline, $4 \mathrm{~mm}$ anterior to the coronal suture, and $2 \mathrm{~mm}$ below the surface of the skull. The volume of injected solution was equal to the 10ul. After infusion, the injection syringe cannula was left in the brain parenchyma for a minute and then removed slowly. After all, the burr hole was covered with the bone wax and the incision was closed. Animals were placed into the cages with the free access for water and food. The hole in the scalp was covered by the paraform based covering gel. Twenty days later animals were decapitated after intacardiac perfusion with Saline. During 29days the animals were injected with the immune suppressants.

\section{Statistics}

In our calculations we have used t-test (student) for pair comparison as well as ONE-WAYANOVA for the calculation of the significance of the comparable all groups. The results were 
considered statistically significant when $\mathrm{p}$ was lower or equal to 0.05 . In some calculations we used t-student test. There were used sigma Plot 10 and Sigma Stat 10 programs. For the creation of the structural formulas there was used the King Draw program.

\section{Results}

\section{The Impact of The Activating Metal Ions on the PRPS-1.}

Mentioned all statistically significances were between the groups and control (\#). The impact of the ions on the activity of PRPS- 1 was estimated by the addition of different concentrations of $\mathrm{Co}^{2+}, \mathrm{Cu}^{2+}, \mathrm{Mg}^{2+}$ (Figure 2). Addition of the $0.001,0.002,0.004 \mathrm{mg}$ of the $\mathrm{Co}^{2}+$ into the mixture was mostly increasing the activity of the PRPS-1 activity in comparison with the control - 13,1934 $\pm 1,4805$ vs $17,6013 \pm 0,1465,17,4197 \pm 0,1523,11,3319 \pm 1,4296$. Higher $0.02,0.04,0.08 \mathrm{mg}$ concentrations decreased the activity of the PRPS-1 until 6,9079 $\pm 1,1303$ (p\#<0.05), 7,2726 $\pm 1,2437$ $(p \#<0.05), 10,3969 \pm 2,1931$. Ions of $\mathrm{Cu}^{2}+$ were decreasing the activity of PRPS-1 in dose dependent manner, however, the activity was higher in the presence of the ions in comparison with the control $-13,1934 \pm 1,4805$ vs $18,0173 \pm 0,638,15,8523 \pm 0,0439$, $13,3211 \pm 0,2607$ and high doses were diminishing that activity

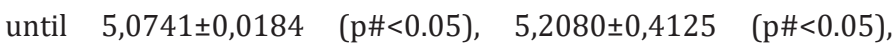
$5,4376 \pm 0,0677$ (p\#<0.05). $\mathrm{Mg}^{2}+$ ions were elevating the PRPS-1 activity in low concentrations in comparison with the control $13,1934 \pm 1,4805$ vs $20,2234 \pm 0,0732,16,6580 \pm 0,1523$, $17,7478 \pm 0,3457(0.02,0.04,0.08 \mathrm{mg}$, respectfully) and elevating in high concentrations $10,4313 \pm 2,1543,11,3982 \pm 2,4453$, $11,2791 \pm 2,3981$ for $0.001,0.002,0.004 \mathrm{mg}$, respectfully.

\section{Influence of the Fosfomycin on PRPS-1 activity.}

Increase of fosfomycin concentration $(0.001,0.002,0.004$, $0.02,0.025,0.04,0.05,0.08$ ) was mostly elevating the activity of PRPS-1 in comparison with the control - 13,1934 $\pm 1,4805$ vs $15,1302 \pm 0,3240, \quad 15,1471 \pm 0,6372,15,5051 \pm 0,6372,16,2303 \pm 0,04$ $78,18,9460 \pm 0,4775,16,7487 \pm 0,5601,21,5710 \pm 1,7959$ (p\#<0.05) $18,8024 \pm 0,5771 \quad(\mathrm{p} \#<0.05), 19,4001 \pm 0,0879(\mathrm{p}<0.04)$, (Figures 2A- 2D).
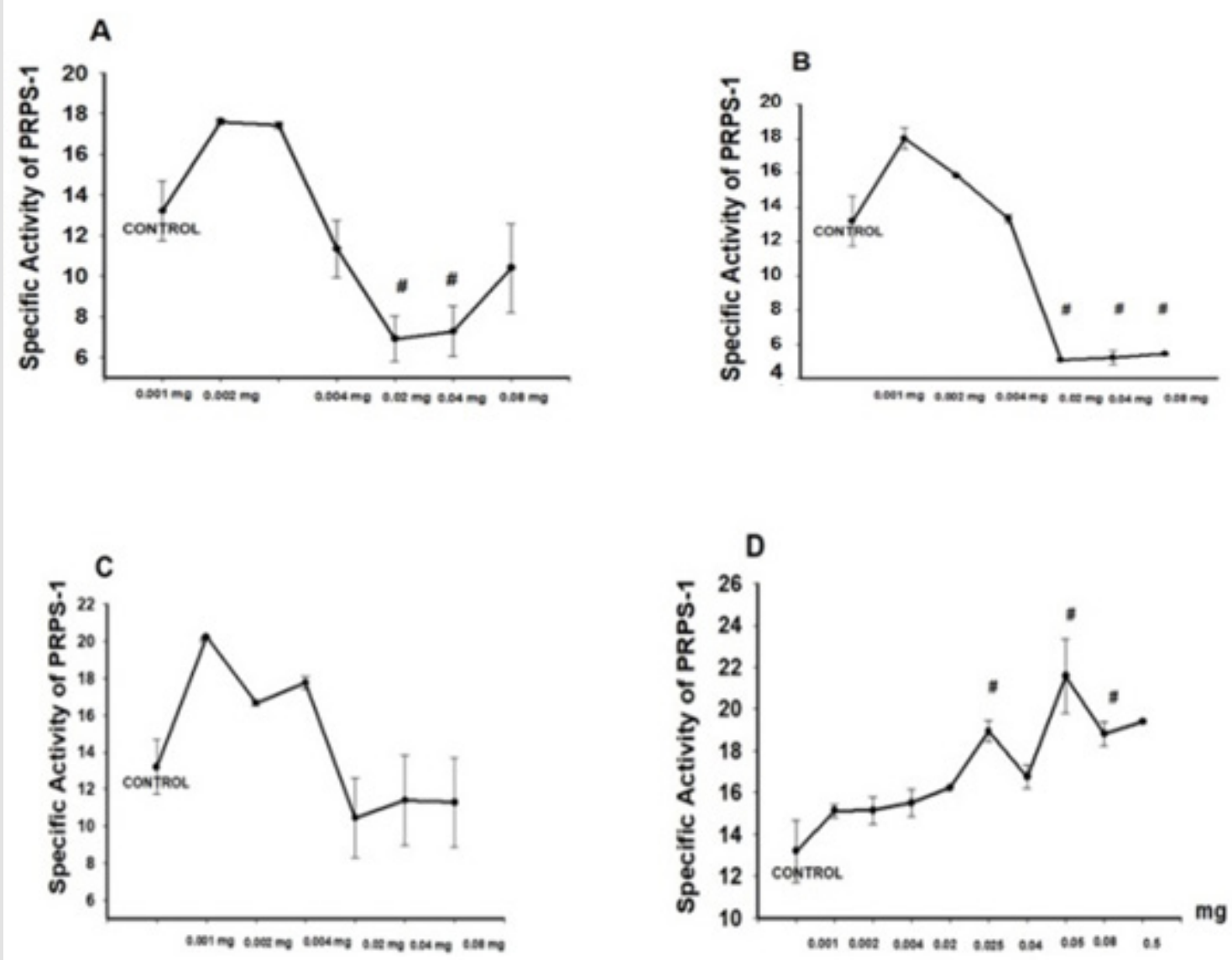

Figure 2: Impact of the effectors on the activity PRPS-1. Final $1 \mathrm{ml}$ solution was containing OPRT, PRPS1 orotate, ribose-5 phosphate, tris buffer ( $\mathrm{pH}=7.4)$, as well as ATP. Incubation was performed during 60 minutes at $36.6 \mathrm{C}$. Addition of ascorbic acid/sulfuric acid/ammonium molybdate solution/antimony potassium tartrate promoted formation of the stable blue color during 10 minutes. The absorbance of the solution was measured at $730 \mathrm{~nm}$ (Cary 60, Agilent, USA). A. Influence of the Co ${ }^{2+}$ on the activity PRPS-1. B. Influence of the $\mathrm{Cu}^{2+}$ on the activity PRPS-1. C. Influence of the $\mathrm{Mg}^{2+}$ ions on the activity PRPS-1. D Influence of the fosfomycin on the activity PRPS-1. It was applied student $t$-test and $\mathrm{p} \#<0.05$. 


\section{Impact of the Inhibitors on PRPS-1 activity.}

Sulfuric acid ions in the quantity of $0.04 \mathrm{mg}$ as well as adenosine were decreasing the activity of PRPS- 1 activity in comparison with the $100 \%$ control $98,7634 \pm 1,2450,93,2074 \pm 0,0932 \quad(\mathrm{p}<0.05)$, (Figure 3).

\section{Low Concentration of SO42- influence on PRPS-1 activity.}

Low concentration of S042- were elevating PRPS-1 in dose dependent manner in comparison with control-13,1934 $\pm 1,4805$ vs18,0144 $\pm 0,8935,18,7937 \pm 0,0674,20,2790 \pm 0,2051 \quad(\mathrm{p}<0.05)$, (Figures 3A-3B).
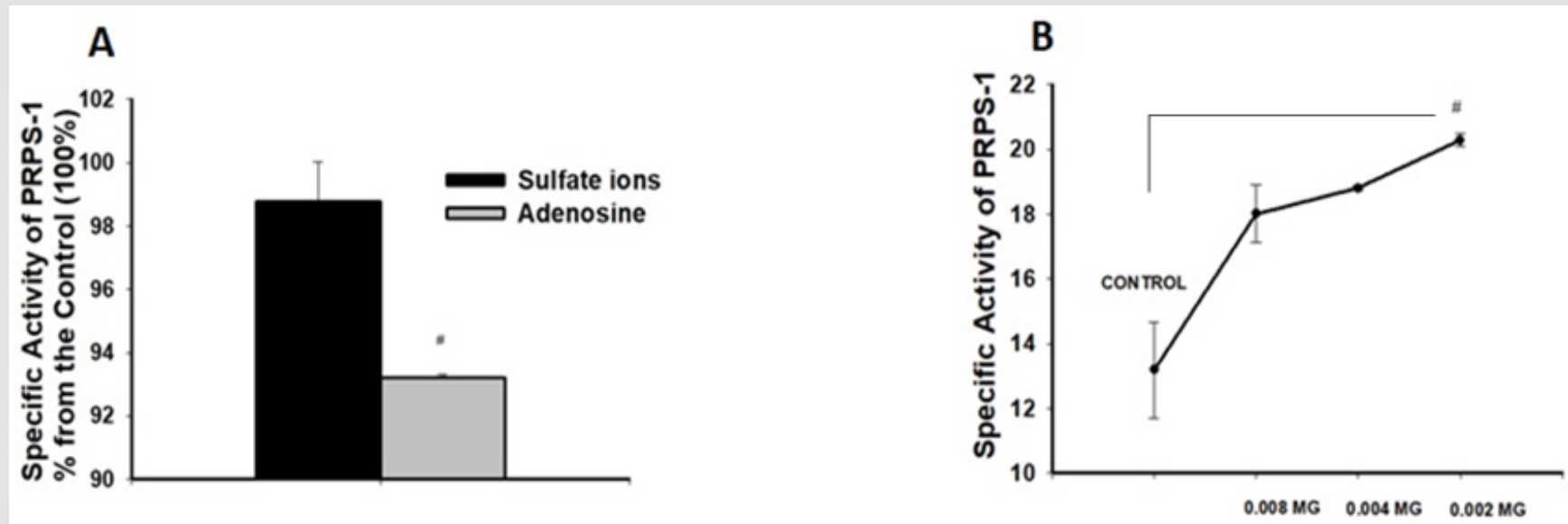

Figure 3: Influence of the sulfate ions as well we adenosine on the activity of the PRPS-1.

A. Impact of the sulfate ions high concentration and adenosine on the activity of PRPS- 1 . We added 0.04 mg of the sulfate ions into the reactive mixture. Adenosine was added in the same quantity. The inhibition percentile was calculated from the control specific activity, which was accounted as the $100 \%$. Measurements were performed by the Cary 60 spectrophotometer at $730 \mathrm{~nm}$ wavelength. The difference between control group and adenosine were statistically significant, $\mathrm{p} \#<0.05$, $\mathrm{t}$-student test.

B. Influence of the low concentrations of the sulfate ions on the activity of PRPS-1. It was applied ONE-WAY-ANOVA for calculation of the significance and $\mathrm{p} \#<0.04$.

\section{Measurement of the PRPS-1, ADA-2 as well as XOR activities in the settings of experimental GB.}
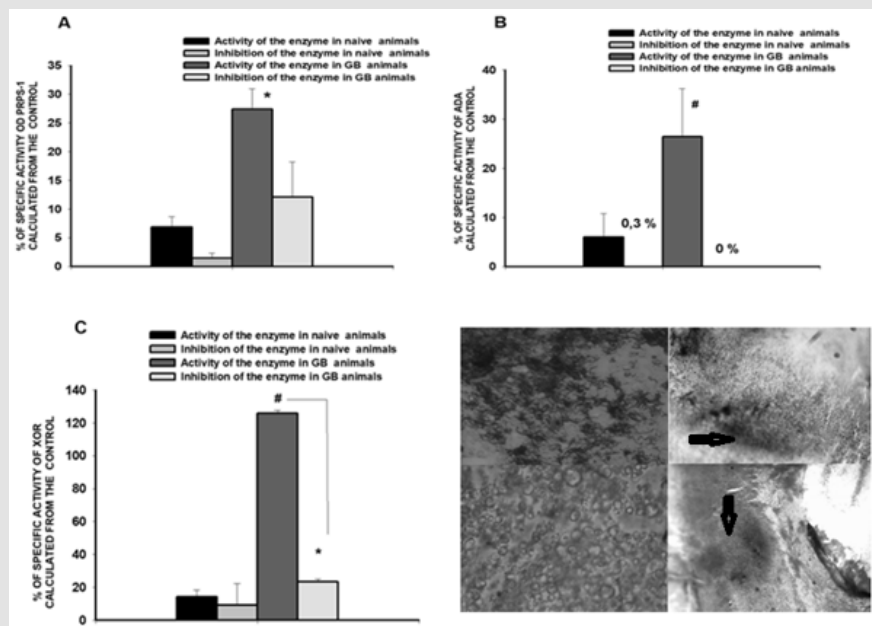

Figure 4: Determination of PRPS-1, ADA and XOR activities in serum of scheme vs GB rats.

A. PRPS- 1 activity in control (first two colums) vs GB rats $\left(3^{\text {th }}, 4^{\text {th }}\right.$ columns).

B. ADA activity in control and GB rats.

C. XOR activity in the control and GB rats.

D. D1, D2. Glioblastoma cells culture: D2-light microscopy with 10x objective and D1 is the Methyl Green same culture. D3, D4. Methyle Green stained slices of the brain of the animals suffering from glioblastoma $(n=6)$. It is clearly seen the hippocampus area on the figure D (4X objective, light microscopy with the 1800 magnifications (Boeco, Germany) and accumulation of the chromatin on the figure D3 with 10X objective magnification. Arrows are indicating the areas of tissue damage. The statistical significance was noticed between naïve animals and GB aniamls comparison groups without the inhibitors for the all 3 enzymes ( $\mathrm{p} \#<0.05$, student $\mathrm{t}$-test, $\mathrm{p} \#<0.03$ for PRPS-1 activity evaluation, student $\mathrm{t}$-test) and inside the GB group for XOR activity measurement $\left(\mathrm{p}^{*}<0.05\right.$, student $\mathrm{t}$-test). 
PRPS- 1 activity (\% from the control) was in naïve animals equal to $6,8737 \pm 1,8079$ (without the inhibitor); after the addition of the inhibitor it was diminished until 1,4136 $\pm 0,9500$ (with the inhibitor inhibitor) vs glioblastoma suffering animals 27,3567 $\pm 3,5750$ (without the inhibitor); $12,0703 \pm 6,1529$ (with the inhibitor); ADA activities for the same comparison groups were 5,9862 $\pm 4,7916$; $0,3000 \pm 0,0000$ vs $26,4606 \pm 9,7808 ; 0,0000 \pm 0,0000$, whereas the XOR activity was $14,1968 \pm 4,2366 ; 9,1332 \pm 13,2417$ vs $125,8324 \pm 1,8673 ; 23,4042 \pm 1,7613$. The statistical significance was noticed between naïve animals and GB animals comparison groups without the inhibitors for the all 3 enzymes ( $\mathrm{p} \#<0.05$, student t-test) and inside the GB group for XOR activity measurement ( $\mathrm{p}^{*}<0.05$, student t-test), (Figures 4A-4D). As the inhibitors for PRPS-1 were serving high concentration of S042- ions, for ADA desoxyadenosine and for XOR- allopurinol.

\section{Discussion and Conclusions}

$\mathrm{Mg}^{2+}$ forms a complex with ATP (Mg-ATP) to act as the actual substrate of PRPS- 1 although other divalent cations, such as Mn2+, $\mathrm{Ni} 2+, \mathrm{Co}^{2+}$ or $\mathrm{Cd}^{2+}$ can serve as the substitutes for $\mathrm{Mg} 2+$ with relatively lower activity [13-15,19,20,32]. Phosphate has multiple effects on the activity and structure of the enzyme. It usually acts as an activator for the activity of bacterial and mammalian PRSPs although $\mathrm{SO}^{2-}$ can mimic the effect of phosphate at approx. 10-fold higher concentrations $[11,13,16,19,33]$. However, phosphate or $\mathrm{SO}^{2-}$ has to compete with the inhibitor ADP at the same allosteric site for their function. That is the reason why high concentration of SO $4^{2-}$ in our experiments were suppressing the PRPS- 1 activity whereas the low concentrations had the opposite impact.

Mostly the all ions in low concentrations as well as fosfomycin had the activating PRPS-1 character and might be used as the potential compounds to trigger the biosynthesis of the purines and pyrimidine, which might serve as the basis for the stimulation of the regenerative processes. In the settings of GB it was notable the elevation of the PRPS-1, ADA as well as XOR activities. We propose, PRPS-1 activation is evidencing about the cells pathological proliferation in the settings of experimental GB. Regulation of PRPS- 1 activity by the microelements might control the growth and proliferation of atypical glial cells. Adenosine deaminase [34] is a key enzyme in metabolism of purines. It catalyzes the irreversible hydrolysis of adenosine into inosine and ammonia. It has a certain role in maintaining immune competence. The consequence of some point mutations in active catalytic center of ADA resembles as a phenotypical representation of SCID. It was shown that in humans ADA activity occurs mainly in two distinct isoenzymes and they are referred to as adenosine deaminase $1\left(\mathrm{ADA}^{*} 1\right)$ and adenosine deaminase 2 ( $\left.\mathrm{ADA}^{*} 2\right)$. $\mathrm{ADA}^{*} 1$ exists in two major forms: a monomer of molecular weight 33,000 (small form) and a dimer-combining protein complex with a total molecular weight of 280,000 (large form), earlier called ADA-S and ADA-L.
This complex has no signifcant influence on its catalytic activity. ADA*2 $^{*}$ exists only as a monomer with molecular weight of 100,000 [35-36]. The main immunological function of ADA is regulation of T, B- cells differentiation as well as B-cells proliferation [35]. At sites of inflammation and tumor growth, the local concentration of extracellular adenosine rapidly increases and plays a role in controlling the immune responses of nearby cells. Adenosine deaminases ADA1 and ADA2 (ADAs) decrease the level of adenosine by converting it to inosine, which serves as a negative feedback mechanism. Mutations in the genes encoding ADAs lead to impaired immune function, which suggests a crucial role for ADAs in immune system regulation [37]. We suggest, ADA activity elevation in GB settings is a marker of the activation of the immune system. Group of scientists from Italy came to the conclusion, tumors with high levels of Xanthine Dehydrogenase (XDH) mRNA are characterized by higher expression of several genes encoding pro-inflammatory and immune cytokines, and increased levels of tumor infiltration with immune cells. The group also underlined the existence of great differences in uricogenesis between different types of human tumors making XDH as the molecular biomarkers of the cancer and cancer types [38].

Similar association between the high uricemia with the metabolic syndrome, diabetes, and cancer was suggested by the numerous other authors [39]. In our experiments we noticed the elevation of XOR activity in GB settings in comparison with the scheme, naïve rats. Thus, we suggest, measurement of 3 above mentioned enzymes activities for the characterization of experimental GB might be informative and serves as the diagnostic tool.

\section{Acknowledgment}

The work was made possible because of ANSEF biochem-4414 award (PI: Kristine Danielyan). The work was supported also by the basic funding from National Academy of Science of Armenia as well as the grant from Science Committee of Ministry of Education and Science of Armenia (PI: Samvel G. Chailyan-18T-1F089).

\section{References}

1. Hove Jensen B (1988) Mutation in the phosphoribosylpyrophosphate synthetase gene (prs) that results in simultaneous requirements for purine and pyrimidine nucleosides, nicotinamide nucleotide, histidine and tryptophan in Escherichia coli. J Bacteriol 170: 1148-1152.

2. Hove Jensen B (1989) Phosphoribosylpyrophosphate (PRPP)-less mutants of Escherichia coli. Mol Microbiol 3: 1487-1492.

3. Ramachandra Rao S (2006) Waste Management Series. Chapter 11 Recycling of Water and Reagents.

4. Yen RC, Adams WB, Lazar C, Becker MA (1978) Evidence for X-linkage of human phosphoribosylpyrophosphate synthetase. Proc Natl Acad Sci USA 75(1): 482-485

5. Zoref E, De Vries A, Sperling O (1975) Mutant feedback-resistant phosphoribosylpyrophosphate synthetase associated with purine overproduction and gout. Phosphoribosylpyrophosphate and purine metabolism in cultured fibroblasts. J Clin Invest 56(6): 1093-1039. 
6. Becker MA, Losman MJ, Kim M (1987) Mechanisms of accelerated purine nucleotide synthesis in human fibroblasts with superactive phosphoribosylpyrophosphate synthetases. J Biol Chem 262(12): 55965602 .

7. Roessler BJ, Nosal JM, Smith PR, Heidler SA, Palella TD, et al. (1993) Human X-linked phosphoribosylpyrophosphate synthetase superactivity is associated with distinct point mutations in the PRPS1 gene. J Biol Chem 268(35): 26476-26481.

8. Becker MA, Smith PR, Taylor W, Mustafi R, Switzer RL (1995) The genetic and functional basis of purine nucleotide feedback-resistant phosphoribosyl-pyrophosphate synthetase superactivity. J Clin Invest 96: 2133-2141.

9. Krath BN, Eriksen TA, Poulsen TS, Hove Jensen B (1999) Cloning and sequencing of cDNAs specifying a novel class of phosphoribosyl diphosphate synthase in Arabidopsis thaliana. Biochim Biophys Acta 1430: 403-408

10. Krath BN, Hove Jensen B (2001) Class II recombinant phosphoribosy diphosphate synthase from spinach. Phosphate independence and diphosphoryl donor specificity. J Biol Chem 276: 17851-17856.

11. Eriksen TA, Kadziola A, Bentsen AK, Harlow KW, Larsen S (2000) Structural basis for the function of Bacillus subtilis phosphoribosylpyrophosphate synthetase. Nat Struct Biol 7(4): 303-308.

12. Kadziola A, Jepsen CH, Johansson E, Mc Guire J, Larsen S, (2005) Nove class III phosphoribosyl diphosphate synthase structure and properties of the tetrameric, phosphate-activated, non-allosterically inhibited enzyme from Methanocaldococcus jannaschii. J Mol Biol 354: 815-828.

13. Switzer RL (1969) Regulation and mechanism of phosphoribosylpyrophosphate synthetase. I. Purification and properties of the enzyme from Salmonella typhimurium. J Biol Chem 244(11): 2854-2863.

14. Fox IH, Kelley WN (1971) Human phosphoribosylpyrophosphate synthetase. Distribution, purification, and properties. J Biol Chem 246: 5739-5748.

15. Switzer RL, Sogin DC (1973) Regulation and mechanism of phosphoribosylpyrophosphate synthetase. V. Inhibition by end products and regulation by adenosine diphosphate. J Biol Chem 248: 1063-1073.

16. Roth DG, Shelton E, Deuel TF (1974) Purification and properties of phosphoribosyl pyrophosphate synthetase from rat liver. J Biol Chem 249: 291-296.

17. Roth DG, Deuel TF (1974) Stability and regulation of phosphoribosy pyrophosphate synthetase from rat liver. J Biol Chem 249: 297-301.

18. Gibson KJ, Schubert KR, Switzer RL (1982) Binding of the substrates and the allosteric inhibitor adenosine 5'-diphosphate to phosphoribosylpyrophosphate synthetase from Salmonella typhimurium. J Biol Chem 257: 2391-2396.

19. Hove Jensen B, Harlow KW, King CJ, Switzer RL (1986) Phosphoribosylpyrophosphate synthetase of Escherichia coli. Properties of the purified enzyme and primary structure of the prs gene. J Biol Chem 261: 6765-6771.

20. Arnvig K, Hove Jensen B, Switzer RL (1990) Purification and properties of phosphoribosyldiphosphate synthetase from Bacillus subtilis. Eur J Biochem 192: 195-200.

21. Iizasa T, Taira M, Shimada H, Ishijima S, Tatibana M (1989) Molecular cloningandsequencingofhumancDNAforphosphoribosylpyrophosphate synthetase subunit II. FEBS Lett 244: 47-50.

22. Sonoda T, Taira M, Ishijima S, Ishizuka T, Iizasa T (1991) Complete nucleotide sequence of human phosphoribosylpyrophosphate synthetase subunit I (PRSI) cDNA and a comparison with human and rat PRPS gene families. J Biochem 109: 361-364.
23. Taira M, Iizasa T, Shimada H, Kudoh J, Shimizu N (1990) human testisspecific mRNA for phosphoribosylpyrophosphate synthetase that initiates from a non-AUG codon. J Biol Chem 265: 16491-16497.

24. Nosal JM, Switzer RL, Becker MA (19930) Overexpression, purification, and characterization of recombinant human 5-phosphoribosylpyrophosphate synthetase isozymes I and II. J Biol Chem 268: 1016810175.

25. Fox IH, Kelley WN (1973) Human phosphoribosylpyrophosphate (PPribose-P) synthetase: properties and regulation. Adv Exp Med Biol 41: $79-86$

26. Fox IH, Kelley WN (1972) Human phosphoribosylpyrophosphate synthetase. Kinetic mechanism and end product inhibition. J Biol Chem 247: 2126-2131.

27. Tang W, L iX, Zhu Z, Tong S, Li X, et al. (2006) Expression, purification, crystallization and preliminary X-ray diffraction analysis of human phosphoribosyl pyrophosphate synthetase 1 (PRS1). Acta Cryst F62: 432-434.

28. Li S, Lu Y, Peng B, Ding J (2007) Crystal structure of human phosphoribosylpyrophosphate synthetase 1 reveals a novel allosteric site. Biochem J 401(1): 39-47.

29. Danielyan KE, Vardanyan, R, Paronyan ZK, Barkhudaryants IM, Bisharyan MS (2018) PRPS-1 is a regulative for neuroprotection and cells regenerative proliferation. Biomolecules and Biochemistry 2(1): 6-10.

30. Sullivan Brown J, Bisher ME, Burdine RD (2011) Embedding, Serial Sectioning and Staining of Zebrafish Embryos Using JB- ${ }^{\mathrm{TM}}{ }^{\mathrm{R}}$ Resin. Nat Protoc 6(1): 46-55.

31. Mattson MP, Ruchlik B (1992) Cell culture of cryopreserved human fetal cerebral cortical and hippocampal neurons: neuronal development and resposes to trophic factors. Brain Research 552: 2004-2014.

32. Willemoes M (1997) Hove-Jensen B. Binding of divalent magnesium by Escherichia coli phosphoribosyl diphosphate synthetase. Biochemistry 36: $5078-5083$

33. Meyer LJ, Becker MA (1977) Human erythrocyte phosphoribosylpyrophosphate synthetase. Dependence of activity on state of subunit association. J Biol Chem 252: 3919-3925.

34. Ficara F, Herna D, Mocchetti C, Carballido Perrig N, Sara Deola GA, et al (2004) IL-3 or IL-7 Increases ex Vivo Gene Transfer Efficiency in ADASCID BM CD34+ Cells while Maintaining in Vivo Lymphoid Potential. Mol Therapy 10(6): 1012.

35. Cristalli G, Constanzi S, Lambertucci C, Lupidi G, Vittori S, et al. (2001) Adenosine deaminase: functional implications and different classes of inhibitors. Med Res Rev 21(2): 105-128.

36. Cowan MJ, Brady R, Widder KJ (1986) Elevated erythrocyte adenosine deaminase activity in patients with acquired immunodeficiency syndrome. PNAS 83: 1089.

37. Kaljas Y, Liu C, Skaldin M, Wu C, Zhou Q et al. (2017) Human adenosine deaminases ADA1 and ADA2 bind to different subsets of immune cells. Cell Mol Life Sci 74(3): 555-570.

38. Saidak Z, Louandre C, Dahmani S, Sauzay C, Guedda S, et al. (2018) A pancancer study of the transcriptional regulation of uricogenesis in human tumours: pathological and pharmacological correlates. Biosci Rep 38(5).

39. Garcia Gil M, Camici M, Allegrini S, Pesi R, Petrotto E (2018) Emerging Role of Purine Metabolizing Enzymes in Brain Function and Tumors. Int J Mol Sci p. 1. 
ISSN: 2574-1241

DOI: 10.26717/BJSTR.2019.24.003988

Kristine Edgar Danielyan. Biomed J Sci \& Tech Res

(c) This work is licensed under Creative

Submission Link: https://biomedres.us/submit-manuscript.php

BIOMEDICAL
RESEARCHES $\quad \begin{aligned} & \text { Assets of Publishing with us } \\ & \text { - Global archiving of articles }\end{aligned}$

